\title{
Agricultura familiar e a relação rural/urbano no agreste de Itabaiana/SE
}

\section{Family farming and rural/urban ratio in the wild of Itabaiana/SE}

\author{
João Ernandes Barreto Nascimento \\ joaoernandesbarreto@hotmail.com \\ Geógrafo licenciado pela Universidade Federal de Sergipe (UFS). Mestrando em \\ Geografia (bolsista da Pró-reitoria de Pesquisa e Pós-Graduação da UESB), vinculado ao \\ Programa de Pós-graduação da Universidade Estadual do Sudoeste da Bahia - \\ PPGeo/UESB
}

\section{José Eloízio da Costa}

eloizio.npgeo@gmail.com

Graduado em Geografia - Doutorado em Geografia pela Universidade Estadual Paulista - Campus de Rio Claro (1999). Professor Associado I do Departamento de Geografia e membro permanente do Programa de Pós-Graduação em Geografia da Universidade Federal de Sergipe.

\section{Fernanda Viana de Alcantara}

nandanpgeo@yahoo.com.br

Doutora em geografia pela Universidade Federal de Sergipe (UFS), com Estágio do Programa de Doutorado Sanduíche - CAPES na Universidade de Lisboa. Professora adjunta no curso de Licenciatura e Pos-Graduação em Geografia do Departamento de Geografia e Vice-Coordenadora do Programa de Pos-Graduação em Geografia da Universidade Estadual do Sudoeste da Bahia.

\section{Marcelo Alves Mendes}

marcelomendesufs@gmail.com

Graduado em Geografia Licenciatura pela Universidade Federal de Sergipe (2002), mestrado (2005) e doutorado (2012) em Geografia Agrária e Regional pela UFS. Atualmente é professor adjunto III no curso de Geografia (DGEI/UFS). 


\title{
RESUMO
}

O presente trabalho busca discutir a relação rural/urbano na microrregião do Agreste de Itabaiana, destacando elementos que caracterizam as novas ruralidades do espaço rural e a importância da feira, principalmente, para os agricultores familiares que não possuem articulação para buscar novos mercados. A pesquisa de campo realizada nos domicílios rurais (aplicando-se 87 questionários) da microrregião e no mercado municipal de Itabaiana/SE (30 questionários), foram os caminhos para o levantamento dos dados primários, buscando relacionar com dados secundários do IBGE. É possível destacar que, embora os agricultores familiares do Agreste de Itabaiana enfrentem desafios socioeconômicos e sejam dependentes da intervenção do Estado, pode-se verificar novas ruralidades nesse espaço geográfico, além de poder demonstrar a origem e o destino dos produtos comercializados, verificando a presença do atravessador e as cadeias curtas na dinâmica produtiva das unidades familiares.

Palavras chave: Agricultura familiar, rural/urbano e comercialização.

\begin{abstract}
The present work seeks to discuss the rural/urban ratio in micro region the wild of Itabaiana, highlighting elements that characterize the new rurality and the importance of the fair, mainly for family farmers who do not have joint to search for new markets. Field research conducted in rural households (87 applying questionnaires) of the micro region and in the municipal market of Itabaiana/SE (30 questionnaires), were the paths to the survey of the primary data, seeking a relationship with secondary data of IBGE. It is possible to emphasize that, although the family farmers in the Wild of Itabaiana face economic challenges and are dependent on the State, you can check for new in this geographical area, besides rurality could demonstrate the origin and the destination of the products marketed by checking the presence of the middleman and short chains on productive dynamics of family units.
\end{abstract}

Keywords: Family agriculture, rural/urban and marketing. 


\section{Introdução}

O meio rural brasileiro vem passando por transformações, tais como a disseminação da tecnologia e a incorporação de novos mercados de trabalho, fazendo-se necessário ampliar o olhar e o debate em torno das questões que evolvem o fortalecimento da agricultura familiar, principalmente após a parte final do século XX. Sendo assim, a agricultura familiar brasileira apresenta complexidade, principalmente, devido à diversidade presente não apenas no meio rural, assim como, nas áreas urbanas as quais acabam influenciando de forma direta ou indireta as atividades e a forma de se organizar das unidades familiares rurais. Consequentemente, as discussões sobre o fortalecimento da agricultura familiar envolvem diversas questões e consequências em torno da pobreza rural, da geração de renda e da (i) racionalidade econômica, além da inserção tecnológica das unidades familiares, assim como a relação rural/urbano para compreensão das atividades agrícolas e/ou não agrícolas presentes no novo rural brasileiro.

A partir de Mendes (2014), Nascimento, C. (2005) e Schneider (2010), verificase o desequilíbrio socioeconômico presente entre as regiões do Brasil, principalmente se comparado o Nordeste com o Sul. Sendo assim, com base em Piketty (2014) e Sen (2010), é possível afirmar que o Estado é um relevante agente que poderá possibilitar a diminuição das desigualdades existentes no sistema econômico vigente. Nessa perspectiva, Abramovay (2003) destaca que, diante da nova forma de trabalho e econômica de se organizar dos agricultores familiares, torna-se importante fortalecer o meio rural, principalmente em áreas pobres, proporcionando aos agricultores inseridos nesses locais, o aumento na capacidade de investimento, pois quanto mais pobres forem essas famílias, menor será a capacidade de inserção e mobilidade social sem a intervenção do Estado.

A microrregião do Agreste de Itabaiana está localizada na porção central do estado de Sergipe, sendo composta por sete municípios, tendo como principal município Itabaiana/SE, o qual se destaca tanto no aspecto populacional (município mais populoso da microrregião) quanto econômico, sendo as principais atividades econômicas ligadas aos setores da indústria e serviços, como destaca Carvalho; Costa (2011), no entanto, é possível ressaltar que as atividades ligadas a agricultura exercem grande importância econômica na microrregião, principalmente, nos demais municípios que possuem apenas o setor público como fonte para empregos. 


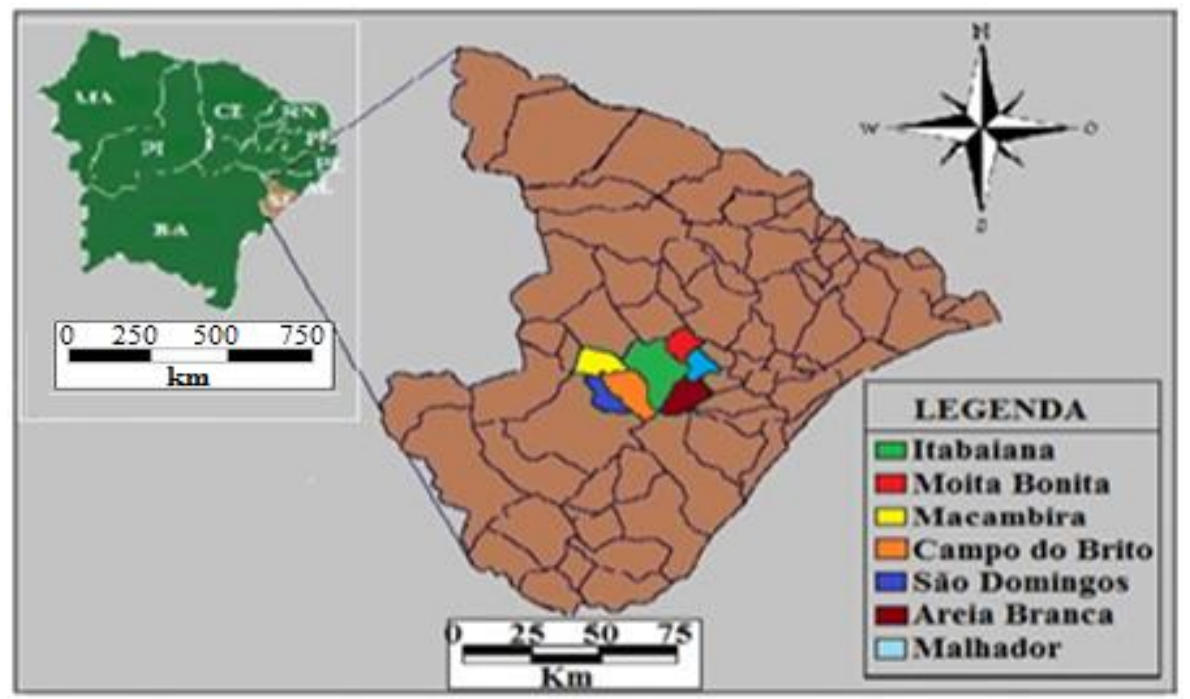

Figura 01: Microrregião do Agreste de Itabaiana.

Fonte: Instituto Brasileiro de Geografia e Estatística (IBGE), setembro, 2017.

O presente trabalho ${ }^{1}$ pretende analisar o alcance comercial existente no mercado municipal de Itabaiana/SE e destacar a importância da feira para a agricultura familiar da Microrregião do Agreste de Itabaiana (figura 01), sendo assim, este estudo busca reunir elementos que contribuam para a compreensão do comportamento da agricultura familiar contemporânea, sendo que as unidades familiares buscam novos mecanismos de sustentação dos indivíduos no meio rural, mas não abandonam as atividades agrícolas. Dessa maneira, torna-se importante destacar a importância do Estado na formulação e aplicação de políticas públicas no Agreste de Itabaiana/SE, onde os agricultores necessitam da orientação dos órgãos públicos competentes, os quais poderão fornecer elementos não apenas financeiro, assim como técnico e extensionista, proporcionando assim, a possibilidade de inserção desses agricultores no sistema produtivo, o qual exige cada vez mais capacidade para diversificar e gerir as rendas.

A agricultura familiar do Agreste de Itabaiana mesmo apresentando alguns elementos que podem aproximá-la do que é entendido como "as novas ruralidades da agricultura brasileira", verifica-se que o espaço geográfico em questão, ainda apresenta

\footnotetext{
${ }^{1}$ Esse texto apresenta resultados de pesquisa financiada com recursos do Conselho Nacional de Desenvolvimento Científico e Tecnológico (CNPq).O presente artigo contou com a colaboração do Grupo de Pesquisa Sobre Dinâmica Rural e Regional da Universidade Federal de Sergipe e credenciado no CNPq (GDRR/UFS/CNPq).
} 
algumas tendências que atuam como desafios para o desenvolvimento rural dessa localidade. Tornando as unidades familiares, dependentes da intervenção do Estado, pois os agricultores encontram-se inseridos em um contexto espacial em que o baixo desenvolvimento socioeconômico e fatores culturais, podem ser destacados como algumas tendências que dificultam a inserção de parte desses agricultores na dinâmica do novo rural.

Nesse sentido, destaca-se a relevância do agricultor ser dinâmico e empreendedor frente às complexidades presentes no meio rural brasileiro contemporâneo, mas é preciso chamar a atenção para o ponto no qual, não basta para o agricultor ser empreendedor se ele não estiver inserido em um contexto espacial que forneça - lhe elementos para que ele possa promover a auto sustentação do domicílio e ampliar os lucros, assim como tornase importante discutir a importância da ampliação da cadeia de comercialização para que o não ocorra a estagnação da produção familiar do Agreste de Itabaiana/SE.

A microrregião do Agreste de Itabaiana/SE será utilizada como recorte espacial de estudo, para fins comparativos com a realidade da nova agricultura brasileira, principalmente a partir da década de 1990, com a implantação de novas atividades ocupacionais no ambiente rural, nesse período que as unidades familiares deixam de dedicar-se exclusivamente a atividades agrícolas e passam a diversificar as atividades laborais. Ao mesmo momento que é esperado verificar as condições de reprodução das unidades familiares, observando o espaço geográfico no qual se encontram inseridas, atentando para as condições de diversificação do trabalho, as quais se encontram ligadas e influenciadas por elementos como educação e renda, importantíssimos na compreensão dos avanços e desafios da agricultura familiar.

Torna-se possível verificar as condições de reprodução das unidades familiares e a dinâmica que envolve a área onde se encontram localizadas, para compreender a realidade e as possibilidades dos agricultores familiares dos municípios em questão é preciso compreender e relacionar os fatores sociais, econômicos e culturais presentes nas relações estabelecidas. Ao mesmo tempo, o referido trabalho busca compreender o processo de afirmação e/ou expropriação das famílias rurais e as condições de trabalho e sobrevivência no recorte espacial analisado diante do processo de modernização e dos avanços técnicos na agricultura familiar brasileira.

\section{Procedimentos técnicos e metodológicos}


Ressalta-se o levantamento e revisão de literatura, atentando-se para as discussões referentes aos desafios e perspectivas que envolvem a agricultura familiar, assim como, questões relacionadas às tendências e possibilidades das novas formas de organizar-se da agricultura familiar e os rebatimentos para as unidades familiares da combinação de atividades agrícolas e não agrícolas. Graziano (1997; 2010), Abramovay (1990; 2003) e Schneider (2000), trazem discussões no cenário nacional, relacionas a agricultura familiar e a alteração do comportamento do padrão agrário e agrícola brasileiro. No caso do Nordeste, é importante ressaltar autores como Cardoso (2013) Nascimento, C. (2005) e Mendes (2014), os quais discutem as novas ocupações dos domiciliados rurais da região, e consequentemente, relacionando. Destaca-se a relevância de autores como Lopes (2009) e Nascimento, J; Mendes (2015), onde sobre as tendências e desafios da agricultura familiar sergipana.

Este trabalho tem como um de seus principais procedimentos metodológicos, a sistematização dos dados primários coletados em Programa Institucional de Bolsas de Iniciação Cientifica da Universidade Federal de Sergipe (Itabaiana, Macambira, São Domingos, Malhador e Campo do Brito, 2013/2014 pesquisas de campo) e (Areia Branca e Moita Bonita, 2014/2015 pesquisas de campo), sendo que, o período 2015/2016 correspondeu à união, análise e atualização do universo de questionários aplicados nos sete municípios da microrregião do Agreste de Itabaiana.

Destaca-se a realização de trabalho de campo com a aplicação de 86 questionários e entrevistas nos sete municípios que formam a microrregião do Agreste de Itabaiana/SE, onde buscou-se entender as principais atividades desenvolvidas pelos agricultores familiares e conhecer a realidade socioeconômica dos domicílios rurais. Também foi realizado trabalho de campo no mercado municipal de Itabaiana/SE (no ano de 2016) com a realização de 30 questionários e entrevistas semiestruturadas com os comerciantes inseridos no mercado municipal do município de Itabaiana/SE, buscando entender a origem e o destino dos produtos agrícolas comercializados no mercado municipal de Itabaiana/SE, sendo caminhos indispensáveis para o levantamento de dados primários, e, percepção das condições de produção e comercialização dos produtos agrícolas, além da relação rural/urbano que marca o espaço analisado. Também, ressalta-se a realização da coleta e sistematização de dados secundários no Instituto Brasileiro de Geografia e Estatística (IBGE). 


\section{A relação rural/urbano e as transformações do espaço}

Para Mendes (2014), foi a partir da segunda metade do século passado, impulsionado pelos avanços técnico-científicos, que o espaço mundial tem se reestruturado em ritmo intenso, propiciado pelos avanços tecnológicos e pela integração dos países por meio da integração/desintegração econômica global. Tal progresso tecnológico tem sido o carro-chefe no processo de expansão do sistema capitalista urbano-industrial, que no seu estágio de maturidade se ramifica em direção a novos espaços considerados no primeiro momento como áreas de economia pré-capitalista. Com isto, diante da crise econômica e política enfrentada pelos países centrais a partir da década de 1950, houve uma política de incentivo ao processo de descentralização industrial em direção aos países subdesenvolvidos, como países asiáticos, africanos e latino-americanos, entre eles o Brasil.

Nesse contexto, a agricultura, como parte do processo, foi inserida principalmente no que se refere à produção e consumo. Assim, a partir da inserção da agricultura no mercado capitalista, os efeitos foram a ampliação do desemprego estrutural e da fome em escala global, pois tal modernização veio beneficiar o grande produtor rural, excluindo deste processo o pequeno produtor que não possuía capital e informação para se inserir nas mudanças da agricultura. Nestes termos, a importância do enfoque da diversificação produtiva no meio rural e sua relevância social tornaram a pluriatividade uma das alternativas para a agricultura familiar nos países centrais e posteriormente na América Latina. A partir do desencadeamento de atividades não-agrícolas no meio rural, as famílias de agricultores tiveram que reestruturar o modo de produzir e de trabalhar, tendo em vista que ao menos um membro da família irá exercer atividade laboral fora da unidade que forma o núcleo familiar.

No caso brasileiro, se for utilizada a concepção da associação entre descentralização industrial e pluriatividade, torna-se necessário entender o contexto histórico-econômico do processo de industrialização e de especialização da agricultura, pois tal processo foi lento e tardio em relação aos países centrais, e principalmente no Nordeste. Portanto, assim como o processo de industrialização difusa, a noção sobre a pluriatividade agrícola processou-se mais intensamente a partir da década de 1990 e, claro de forma desigual e combinada no espaço rural brasileiro.

É consenso entre os estudiosos, que é a partir do final do século XX, com o surgimento de novas demandas e atividades ocupacionais no meio rural, o agricultor deixa de dedicar-se exclusivamente as atividades agrícolas e passa a diversificar o trabalho 
dentro da unidade familiar. Ao mesmo momento, vale ressaltar que as condições de reprodução das unidades familiares, irão estar associadas as condições de vida de cada contexto social, no qual as famílias estarão inseridas. Sobre as transformações do rural, vale ressaltar que;

O rural vem se reconfigurando devido as transformações socioespaciais que se despontaram nas últimas décadas, desmistificando a ideia que associava rural, como um modo de vida ultrapassado e o urbano como avançado. Essa analise toma-se como base, as modificações do cenário rural brasileiro, mediante a reestruturação das forças produtivas, bem como o advento da globalização, tendo esta como uma fase do modo de produção capitalista. Essas transformações na dinâmica socioespacial assumem grandes evidencias, no período do meio técnico-científicoinformacional, mais precisamente no Brasil a partir de 1970. (Rocha \& Santos, 2015, p.2).

Nessa perspectiva, que a Pluriatividade surge como um fenômeno marcante do "novo rural brasileiro", a qual encontra-se ligada e influenciada por fatores socioeconômicos e representa um dos principais elementos que caracterizam a "urbanização do meio rural". Nessa perspectiva, com base no pensamento de Lefebvre (2001), pode-se considerar infundada a separação entre o rural e o urbano para aqueles que buscam entender a totalidade das relações sociais e explicar as contradições da sociedade contemporânea;

Não há a menor dúvida de que a separação entre a cidade e o campo mutila e bloqueia a totalidade social; ela depende da divisão do trabalho material e social que encarna, que projeta sobre o território. Nessa separação, compete ao campo o trabalho material desprovido de inteligência; à cidade pertence o trabalho enriquecido e desenvolvido pelo intelecto, compreendendo a as funções de administração e comando. (Lefebvre, 2001, p. 50).

É a partir do final do século XX, com o surgimento de novas demandas e atividades ocupacionais no meio rural, que o agricultor deixa de dedicar-se exclusivamente às atividades agrícolas e passa a diversificar o trabalho dentro da unidade familiar. Ao mesmo momento, vale ressaltar que as condições de reprodução das unidades familiares, irão estar associadas as condições de vida de cada contexto social.

Com base em Mendes (2013), é possível afirmar a importância de resgatar e estimular a produção e comercialização, consequentemente, fortalecerá a geração de renda para a agricultura familiar, caso contrário, os grandes parcelas da população continuarão migrando para as áreas urbanas, e assim, os problemas sociais deixarão de ser rurais e aumentarão os urbanos, sendo que a alta parcela da população com baixo nível de instrução, é um fato que acaba dificultando não apenas a vida dos agricultores 
familiares, assim como, a permanência do jovem, que se depara em um ambiente com poucas opções e acaba sendo obrigado a sair do meio rural em busca de maiores oportunidades e melhores condições de vida.

Aliada a esses fatores, a necessidade cada vez maior de informação e conhecimento, cria desejos e anseios para que os filhos de agricultores se desloquem em busca das áreas fornecedoras de tais conhecimentos gerando declínio da permanência dos potenciais agricultores no espaço rural. (MENDES, 2013, p. 96).

Para Schneider (2000), a emergência das atividades não agrícolas e da pluriatividade, é decorrente do próprio processo de "urbanização do campo", resultante de um "transbordamento" das cidades e do mercado de trabalho urbano para as áreas rurais situadas em seu entorno. Por isso, que torna-se relevante entender as diferenças que ainda existem entre o rural e o urbano brasileiro, mas mesmo assim, é importante compreender que cada vez mais o rural/urbano encontra-se dependente, sendo um caminho indispensável entender que o rural não é mais sinônimo de atraso e pobreza apenas.

(...) essa redução da população ocupada em atividades agrícolas não significa que haja uma retomada do êxodo rural iniciado na década de 1960. No período recente, especialmente a partir dos anos oitenta, a queda do emprego agrícola tem sido compensada parcialmente pelo crescimento da população rural ocupada em atividades não agrícolas. (SCHNEIDER, 2000, p, 11).

Quando Schneider (2000) analisa o caso da América Latina e do Brasil, especificamente, chamando a atenção para o fato de que embora essa parte do mundo corresponda a países subdesenvolvidos, é evidente o crescimento das ocupações em atividades não agrícolas das pessoas com domicilio rural, por isso, cada vez menos se têm pessoas de áreas rurais ligadas apenas a atividades agrícolas.

A industrialização fez surgir um novo ator no meio rural, que diversifica as atividades ocupacionais, permitindo assim, classificá-lo como agricultor em tempo parcial e busca cada vez mais está inserido no sistema produtivo, sem abdicar atividades agrícolas em alguns dias da semana. Com isso, Graziano da Silva (1997) aponta que;

(...) Em primeiro lugar, aquelas relacionadas com a proliferação de indústrias, em particular das agroindústrias, no meio rural. Em segundo lugar vêm aquelas atividades relacionadas à crescente urbanização do meio rural (como moradia, turismo, lazer e outros serviços) e a preservação do meio ambiente. Finalmente, em terceiro lugar, mas não menos importante nesta rápida caracterização das atividades não agrícolas que vem se desenvolvendo no nosso meio rural, é preciso destacar a proliferação dos sítios de recreio, ou simplesmente chácaras, 
como são chamadas no interior do estado de São Paulo (...). (GRAZIANO DA SILVA, 1997, p.12).

Nesses termos, os desafios da agricultura familiar, principalmente no caso do Nordeste, vão além de problemas como a seca, à medida que, a diversificação do trabalho surgiu como uma alternativa das famílias rurais, consequentemente, a pluriatividade pode representar uma das formas para promover a sustentação das famílias rurais, com a combinação de duas ou mais atividades, sendo que uma delas seja a agricultura. Dessa maneira, a pluriatividade poderá ser uma saída para a família residente em áreas rurais não apenas para a ampliação da renda, como também, para algo que é destacado em Mendes (2014), no qual ele aponta que a importância da pluriatividade para a unidade familiar é determinada por diferentes variáveis;

O princípio básico para demonstrar o significado da pluriatividade está relacionado à conquista da confiança, autoestima e da dignidade dos agricultores familiares, (re) conquistada a partir de atividades que promovem a inserção profissional e social dos agricultores familiares. (MENDES, 2014, p.193).

As famílias rurais recorrem às atividades não agrícolas, não só como uma alternativa para continuar no meio rural, mas também, no caso das famílias pobres, a pluriatividade tem servido como uma ponte para a passagem de uma atividade a outra, e até a saída da situação de pobreza. A partir da discussão sobre a relação/rural urbano, fica evidente a importância de se analisar os aspectos da agricultura familiar em área de transição rural/urbano, onde a mesma irá apresentar as chamadas novas ruralidades tantos nos tipos de atividades desenvolvidas (antes encontradas apenas nas áreas urbanas), tanto na sua morfologia. É nessa perspectiva que verifica-se, na microrregião do Agreste de Itabaiana, a construção de um auto posto a cerca de $10 \mathrm{Km}$ da BR 235 (figura 02), fator que pode acabar refletindo o surgimento de novas atividades no meio rural, melhorias nas condições de vida (através da motorização de algumas atividades dos agricultores familiares). 


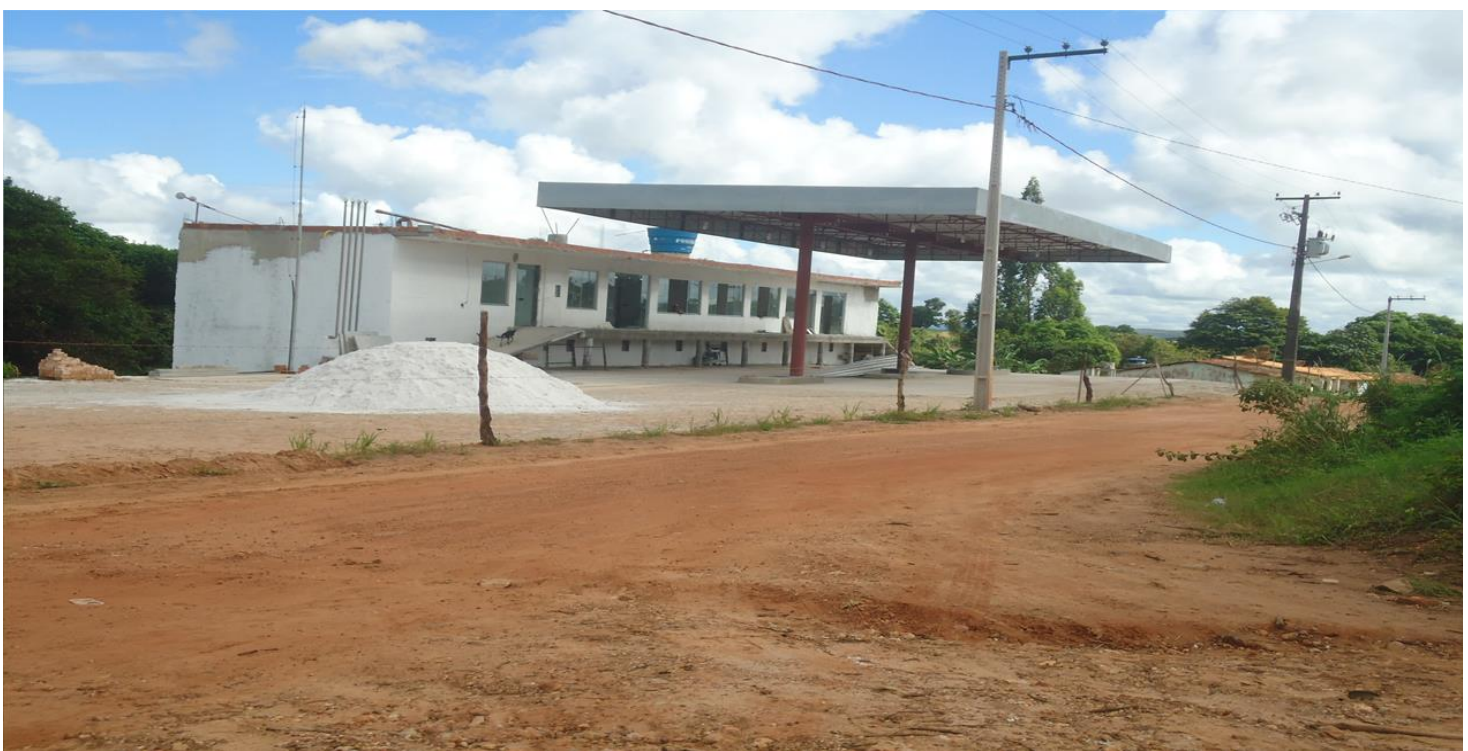

Figura 02 - Construção de auto posto de conbustiveis no Agreste de Itabaiana/SE.

Fonte: Trabalho de campo, junho de (2016).

A partir de Graziano da Silva (1997), é possível afirmar que, as políticas de desenvolvimento rural continuam a ser direcionadas basicamente para reduzir o isolamento das populações rurais (melhoria nos sistemas de transporte e de comunicação) e melhorar as suas condições de vida (habitação, saúde, etc.) e de qualificação (ensino básico e técnico). E assim, não se tem levado em conta o fato de que o meio rural tem necessidades novas, típicas de uma sociedade pós-industrial, como por exemplo, a de estabelecer um zoneamento para definir áreas industriais ou de serviços e de moradia, áreas de preservação ambiental, etc.

Gráfico 01 - Percentual de rendimento médio nos domicílios rurais do Agreste de Itabaiana 2000-2010.

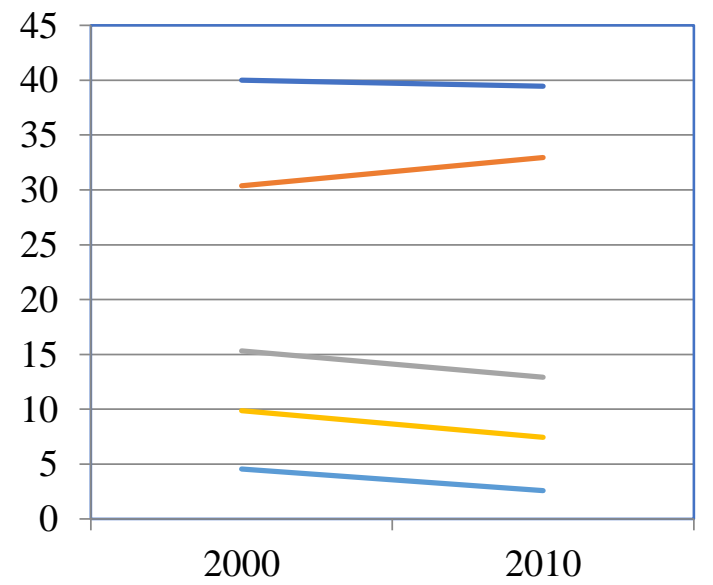

—Menos de 1 salário mínimo

Entre 1 e 2 salários mínimos

Entre 2 e 3 salários mínimos

Entre 3 e 5 salários minímos

- Acima de 5 salários mínimos

Fonte: Instituto Brasileiro de Geografia e Estatística, 2017.

Organização: João Ernandes, Setembro, 2017. 
No gráfico 01, observa-se o crescimento do percentual de domicílios rurais envolvidos em atividades remuneradas com rendimentos inferiores a dois salários mínimos no Agreste de Itabaiana, fato que, acaba sendo um dos agravantes no desenvolvimento da agricultura familiar, sendo que, esses domicílios acabam tendo que enfrentar situações de extrema pobreza, e se tornam cada vez mais dependentes das políticas de transferência de renda do Estado. No entanto, foi visualizado a partir do trabalho de campo realizado, que o meio rural do Agreste de Itabaiana não pode ser associado apenas às condições de extrema pobreza, por ter sido verificado determinada diferenciação no que se refere à dinâmica da agricultura familiar no campo analisado, sendo que, as localidades mais dinâmicas e menos dependentes apenas das atividades agrícolas acabam apresentando melhores condições de vida.

Gráfico 02 - Dados percentuais de escolaridade da população rural jovem com idade de 15-24 anos no Agreste de Itabaiana.

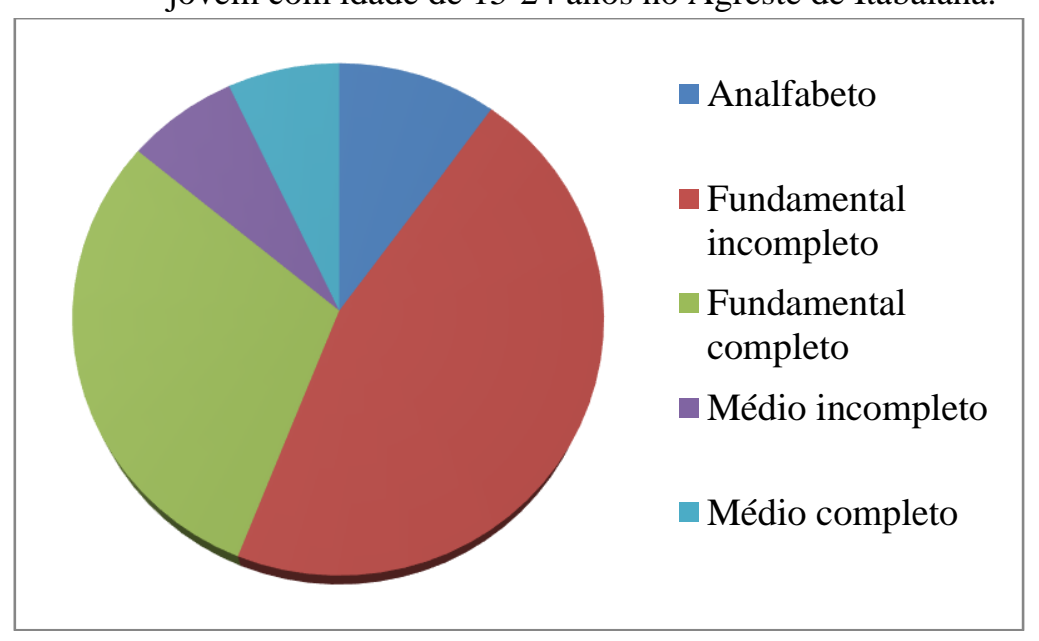

Fonte: Trabalho de campo, Junho, 2016.

Elaborado pelo autor, agosto, 2017.

O gráfico 02 representa os baixos índices de escolaridades que podem ser associados às atividades de baixa remuneração das áreas em questão, o que acaba refletindo nos tipos de atividades não agrícolas realizadas por estes agricultores, e consequentemente, concentrando estas atividades em setores como ajudante de pedreiro, carroceiro e faxineira. Com isso, é possível destacar a importância da combinação de atividades agrícolas e não agrícolas nestas unidades familiares, mas é importante ressaltar que as atividades não agrícolas tendem a se concentrar, cada vez mais, em setores que atribuem baixa remuneração a estes agricultores. Como exemplo de políticas públicas voltadas para os jovens agricultores, o governo federal disponibiliza uma linha de crédito 
específica, Pronaf Jovem, e que, ainda, é pouco acessada por motivos de requisitos profissionalizantes e até mesmo acesso a essa informação. Segundo a SAF/MDA (Secretaria da Agricultura Familiar/ Ministério do Desenvolvimento Agrário) os jovens agricultores, para acessar a linha de crédito perante os agentes financeiros, devem ter concluído ou está cursando o último ano em centros familiares rurais de formação por alternância ou em escolas técnicas agrícolas de nível médio, ter participado de curso ou estágio de formação profissional e ter recebido orientação de uma instituição prestadora de Assistência Técnica e Extensão Rural (ATER).

Nascimento, J; Mendes 2016, também ressaltam a falta de capacidade ou recursos, que os agricultores familiares do Agreste de Itabaiana possuem para agregar valor ao que é produzido ou até mesmo utilizar o que é colhido como matéria prima para a produção de outras mercadorias, daí a surge a importância do Estado, que de forma meio que indireta (segundo os autores) acaba sendo citado pelos agricultores. Nesses termos, o Estado poderia atuar orientando estes agricultores de como utilizar o que é produzido, e até mesmo estruturando financeiramente esse grupo de agricultores. Sendo assim, tornase importante destacar que o Estado vem a se consolidar como um importante agente no processo de desenvolvimento da agricultura familiar não só no município de Itabaiana, mas também na microrregião, onde o mesmo poderá atuar na estruturação do setor, elaborando políticas que possam atender as necessidades e melhorar as condições de reprodução das unidades familiares.

A partir de Nascimento J; Mendes (2015), é percebido que há uma grande concentração de domicílios rurais no Nordeste com rendimentos inferiores a três salários mínimos, apontando para a necessidade de se repensar as políticas públicas para o meio rural, assim como, ações capazes de gerar renda para esses agricultores familiares, ao tempo que, o baixo nível de instrução presente nas unidades familiares tem como consequência a concentração de unidades familiares envolvidas em atividades mal remuneradas.

Segundo Nascimento, J; Mendes (2015) verificou-se melhorias nos índices relacionados à renda e a educação no Nordeste e em Sergipe, e no caso do Agreste de Itabaiana, isso pode ser associado à interiorização dos investimentos do Estado, fato que acaba alterando a dinâmica sócio espacial de todos os setores inseridos nesse contexto espacial, como exemplo pode-se destacar a expansão das instituições de Ensino Federal (UFS e IFS), fator que pode ser considerado como determinante para a melhoria dos índices de educação, não apenas do município de Itabaiana, mas também dos municípios 
que compõem a microrregião, como é evidenciado nos dados do estudo de Nascimento, J; Mendes (2015), quando destacam a importância dessas instituições no Agreste de Itabaiana. Cabe ressaltar que os impactos gerados pela melhoria dos índices educacionais ocorridos nas últimas décadas, vão além de questões relacionadas a renda, sendo que a partir do momento em que um dos membros da unidade familiar tem acesso à educação e dá continuidade aos estudos, o mesmo consegue visualizar maiores opções e direitos para o seu contexto social.

\section{A importância da feira para a agricultura familiar}

Com base em estudos feitos por Nascimento, J; Mendes (2015), evidencia-se o caráter empreendedor presente na agricultura familiar do Agreste de Itabaiana, onde os avanços tecnológicos das últimas décadas proporcionaram aos agricultores familiares buscarem novas ocupações sem abdicar das atividades rurais, com isso, o empreendedorismo rural, pode ser considerado como uma das novas ocupações desses agricultores, sendo que, os mesmos, buscam se inserir na dinâmica dos mercados como destaca Abramovay (1990), ainda que seja na forma irracional (na lógica dos mercados), frisada por Nascimento, J; Mendes (2015).

Os estudos sobre empreendedorismo rural ainda são muito recentes e quase que inexistente na geografia, com isso Abramovay (2003) contribui como uma importante base científica para a compreensão dessa categoria da agricultura familiar, a qual, mesmo inserida em áreas pobres, como é o caso da microrregião Agreste de Itabaiana, buscam essa estratégia para o aumento dos rendimentos familiares e acabam alterando a dinâmica das localidades aonde se desenvolvem.

A partir das entrevistas de campo é possível evidenciar dois perfis de agricultores na microrregião do Agreste de Itabaiana; o primeiro apresenta-se muito mais dependente das atividades agrícolas e mais dependente ainda das políticas de transferência de renda do Estado, por este, acabar sendo mais afetado pelas sazonalidades. O segundo, apresentou-se dinâmico e empreendedor, ao tempo em que, o mesmo busca comercializar sua produção nas feiras livres da região, além de não serem caracterizados apenas por se dedicarem as atividades agrícolas, com isso, são responsáveis pela formação de novos empreendimentos, que acabam diferenciando o espaço geográfico em que desenvolvem suas atividades.

No gráfico 03 é possível fazer relação com o pensamento de Graziano (1997), pois, o autor destaca que os avanços técnicos propiciam aos agricultores familiares 
introduzirem novas atividades ao longo da semana de trabalho sem abdicar das atividades agrícolas, já que, os avanços com as tecnologias agrícolas acabam exigindo cada vez, menos tempo direcionado exclusivamente ao plantio e a colheita, dessa forma, assim como, é evidenciada em Mendes (2014), e Nascimento, J; Mendes (2015), a diversificação do trabalho no Agreste de Itabaiana, não significou a diminuição na produtividade dos principais produtos da lavoura da microrregião, pois, verifica-se o aumento da produtividade (em quilograma por hectare), em todos os produtos considerados como principais pelos agricultores familiares e pelo IBGE, exceto a banana e o feijão, os quais se mantiveram constante no período analisado, vale ressaltar ainda, o salto no valor da produção anual (em reais), principalmente, no caso da batata doce e da mandioca, além de os demais produtos se manterem em considerável crescente.

Gráfico 03 - Dados referentes à produção e rendimentos da lavoura no Agreste de Itabaiana 2006-

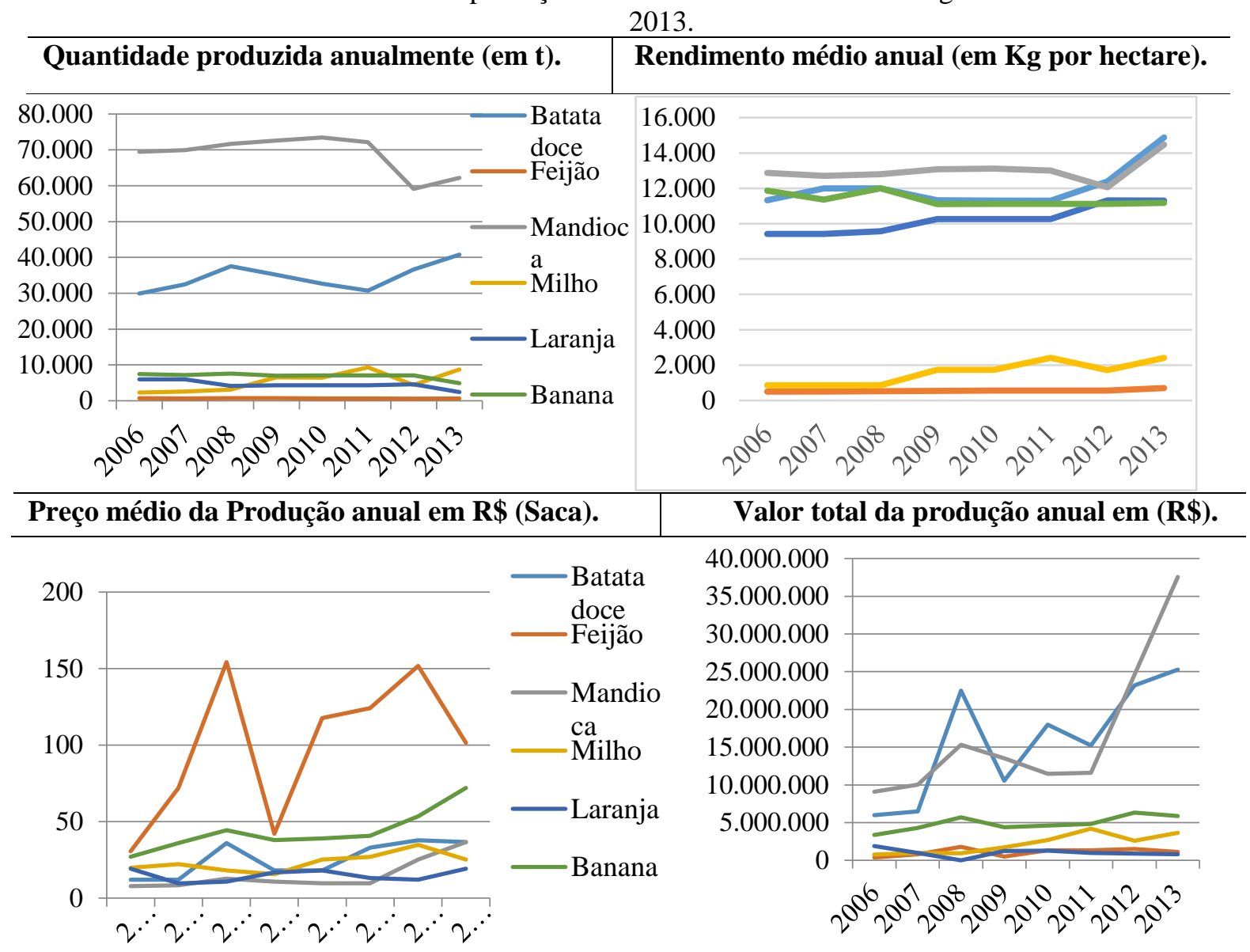

Fonte: Instituto Brasileiro de Geografia e Estatística, 2017.

Organizado pelo autor, Setembro, 2017.

Com base nos dados do IBGE, ainda torna se possível destacar a produção do tomate e do amendoim, os quais, em 2013 atingiram a marca de 1620 t. e 1583 t. 
respectivamente, aonde, embora observe se a queda da produção do tomate no período 2006-2013 (de 3940 t. para 1620 t.) verificou se, o aumento de produção de amendoim no mesmo período, saltando de 514 t. em 2006, para 1583 t. em 2013, com isso, o tomate e o amendoim chegaram a atingir em 2013, o valor total da produção segundo o IBGE, de pouco mais de 2 milhões de reais, e, $R \$ 1.909 .000,00$, respectivamente. No entanto, embora tenha ocorrido a queda na produção da lavoura do tomate em mais de $50 \%$ no período analisado, o valor anual da produção se manteve acima dos $\mathrm{R} \$ 2$ milhões de reais, fator que pode ser associado ao pensamento de Abramovay (1992), quando o autor cita a “imperfeição dos mercados", e assim a queda na produção anual do tomate, propiciou o aumento no valor recebido, algo, que pode ser considerado como positivo para os agricultores, pois, inseriram novas lavouras em suas propriedades, proporcionando o aumento dos lucros e a diversificação produtiva.

Tabela 01 - Número de estabelecimentos agropecuários por área em hectares e dedicados à agricultura familiar/não familiar no Agreste de Itabaiana - 2006.

\begin{tabular}{|c|c|c|c|c|c|c|c|}
\hline $\begin{array}{c}\text { Menos de } 5 \\
\text { (ha) }\end{array}$ & \multicolumn{2}{|c|}{$\begin{array}{c}\text { Mais de } 5 \text { e } \\
\text { menos } 20 \text { (ha) }\end{array}$} & \multicolumn{2}{|c|}{$\begin{array}{l}\text { Mais de } 20 \mathrm{e} \\
\text { menos } 100(\mathrm{ha})\end{array}$} & \multicolumn{2}{|c|}{ Mais de 100 (ha) } & $\begin{array}{c}\text { Produtor sem } \\
\text { terra }\end{array}$ \\
\hline 10756 & \multicolumn{2}{|r|}{1323} & \multicolumn{2}{|c|}{394} & \multicolumn{2}{|l|}{89} & 132 \\
\hline $84,72 \%$ & \multicolumn{2}{|c|}{$10,43 \%$} & \multicolumn{2}{|c|}{$3,11 \%$} & $0,71 \%$ & & $1,04 \%$ \\
\hline \multicolumn{4}{|c|}{ Agricultura familiar } & \multicolumn{4}{|c|}{ Agricultura não Familiar } \\
\hline \multicolumn{2}{|c|}{$\begin{array}{c}\text { Número de } \\
\text { Estabelecimentos }\end{array}$} & \multicolumn{2}{|c|}{$\begin{array}{c}\text { Área dos } \\
\text { Estabelecimentos }\end{array}$} & \multicolumn{2}{|c|}{$\begin{array}{c}\text { Número de } \\
\text { Estabelecimentos }\end{array}$} & & Estabelecimentos \\
\hline \multicolumn{2}{|c|}{11.977} & \multicolumn{2}{|c|}{37.921} & \multicolumn{2}{|r|}{717} & & 36.394 \\
\hline \multicolumn{2}{|l|}{$94,35 \%$} & \multicolumn{2}{|c|}{$51,03 \%$} & \multicolumn{2}{|c|}{$5,65 \%$} & & $48,97 \%$ \\
\hline
\end{tabular}

Fonte: Censo Agropecuário, 2006.

Organização: João Ernandes, Setembro, 2017.

Com base na tabela 01, é possível destacar o fato de, apesar de o número de estabelecimentos agropecuários caracterizados como agricultura familiar representarem a grande maioria dos estabelecimentos (94,35\%), observa-se que em área correspondem a pouco mais da metade do total da microrregião, além de ser possível fazer com o tamanho da propriedade dessas unidades familiares, já que 96,19\% dos estabelecimentos possuem menos de 20 hectares ou são produtores sem terra. Com isso, verifica-se a importância que essas unidades familiares representam para o desenvolvimento da microrregião e seus respectivos municípios, pois, mesmo correspondendo a uma maior subdivisão das terras, são responsáveis pelos principais produtos da lavoura do Agreste de Itabaiana.

Verifica-se que, os domicílios rurais familiares do Agreste de Itabaiana são caracterizados por serem compostos por pequenas propriedades, no entanto, representam 
grande importância na produção agrícola da microrregião, com isso, torna-se importante destacar o pensamento de Mendes (2014), pois, o autor ressalta que, a pluriatividade é caracterizada tanto pela combinação das atividades agrícolas e não agrícolas e/ou para agrícolas, assim como, o autor ainda chama a atenção para o fato de os domicílios familiares pluriativos possuírem uma divisão interna do trabalho que possibilita aos mesmos diversificarem as rendas sem necessitar diminuir a dedicação às atividades agrícola. Dessa maneira, verifica-se que os domicílios pesquisados no Agreste de Itabaiana, buscam diversificar seus rendimentos como estratégia para manter o sustento das unidades familiares. O gráfico 04 representa as fontes de renda citadas nos domicílios pesquisados no Agreste de Itabaiana, onde a renda oriunda do empreendedorismo (produz e comercializa) esteve presente, em mais de $80 \%$ dos domicílios pesquisados, verifica-se ainda a importância do trabalho fora da unidade familiar, e das políticas de transferência de renda do Estado na reprodução dessas unidades familiares.

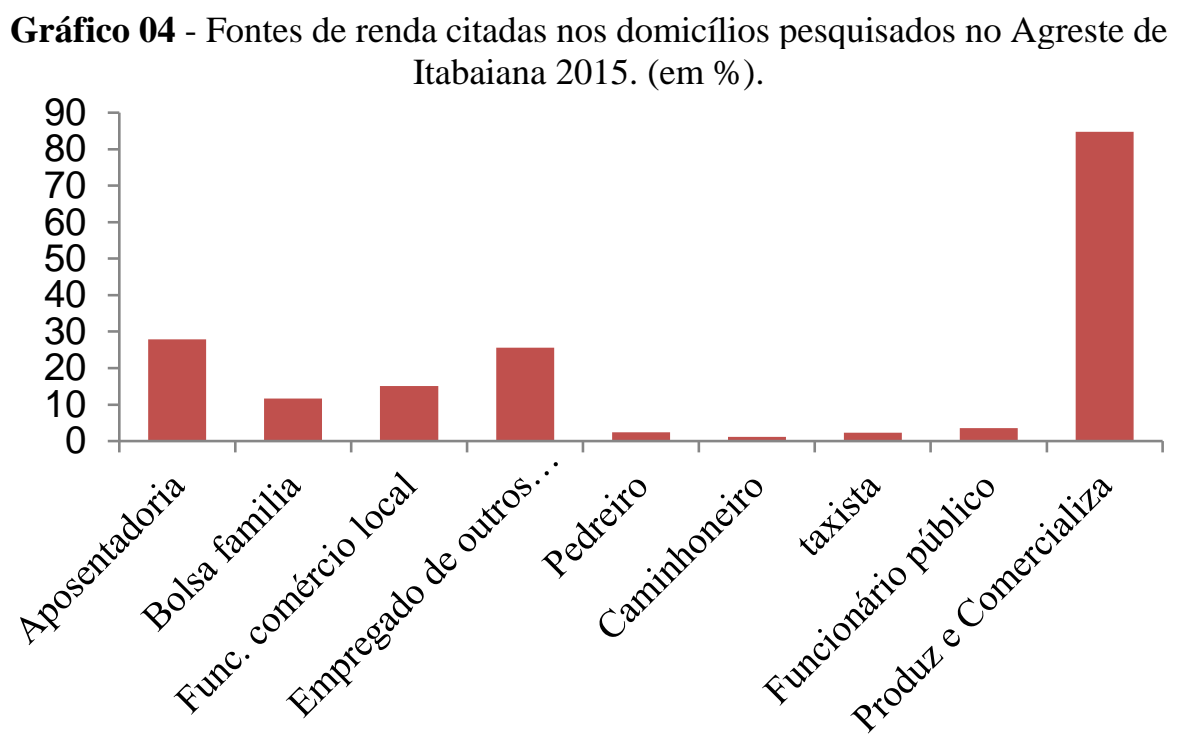

Fonte: Trabalho de campo, setembro, 2017.

Outro elemento importante observado nas pesquisas de campo é a presença do atravessador (gráfico 04), a qual acaba estimulando a produção na lavoura do Agreste de Itabaiana, uma vez que, diferentemente do que acontece em outras localidades esses domicílios tendem a não ser dependente desse atravessador, pois, esse agente acaba sendo impossibilitado de propor um preço mínimo, pelo fato de, as unidades familiares participarem de forma considerável da venda direta ao consumidor através das feiras, elemento que acaba proporcionando a esses agricultores terem a consciência dos preços 
pagos pela produção. Com base nos gráficos (04 e 05), é importante destacar algo observado nas entrevistas de campo onde se verificou a dificuldade em gerenciar economicamente as fontes de renda presentes nos domicílios familiares, ao tempo em que, não apresentaram organização das despesas e rendimentos, pois, o principal argumento desses agricultores é que buscam somente prover o sustento familiar, e, por isso, não organizam as despesas, no entanto, foi observado, que os agricultores pluriativos, apresentam melhores condições de vida e de forma indireta apresentam maiores bens materiais.

Gráfico 05 - Principais destinos da produção dos estabelecimentos rurais do Agreste de Itabaiana 2015. (em \%).

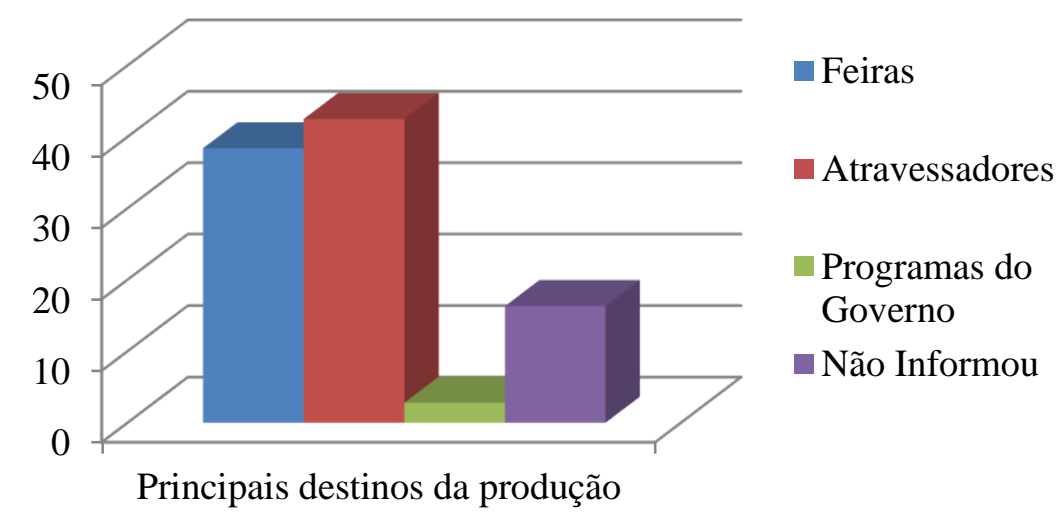

Fonte: Trabalho de campo, 2015.

Organização: João Ernandes, setembro, 2017.

Conforme o pensamento de Abramovay (1992), onde verifica-se que as unidades familiares do Agreste de Itabaiana, mesmo de forma irracional, contribuem e encontramse inseridas no sistema produtivo, com isso, mesmo sendo a pobreza rural um dos principais condicionantes para o desencadeamento da Pluriatividade, como destaca Nascimento, A.(2005). Assim como, destaca Mendes (2013) que a pluriatividade representa um "mecanismo de inserção social no mercado de trabalho, como necessidade de sobrevivência em meio à competitividade criada pela lógica capitalista" (p.111). É nessa perspectiva, que o Estado pode desempenhar um papel fundamental na reprodução dessas unidades familiares, capacitando esses agricultores seja na instrução técnica ou econômica, já que, organizar a diversificação dos rendimentos, acaba se tornando um desafio para essas unidades familiares as quais, acabam destinando os ganhos das rendas fixas (assalariamento) à produção comercial, sem fazer o balanço do retorno financeiro necessário. 


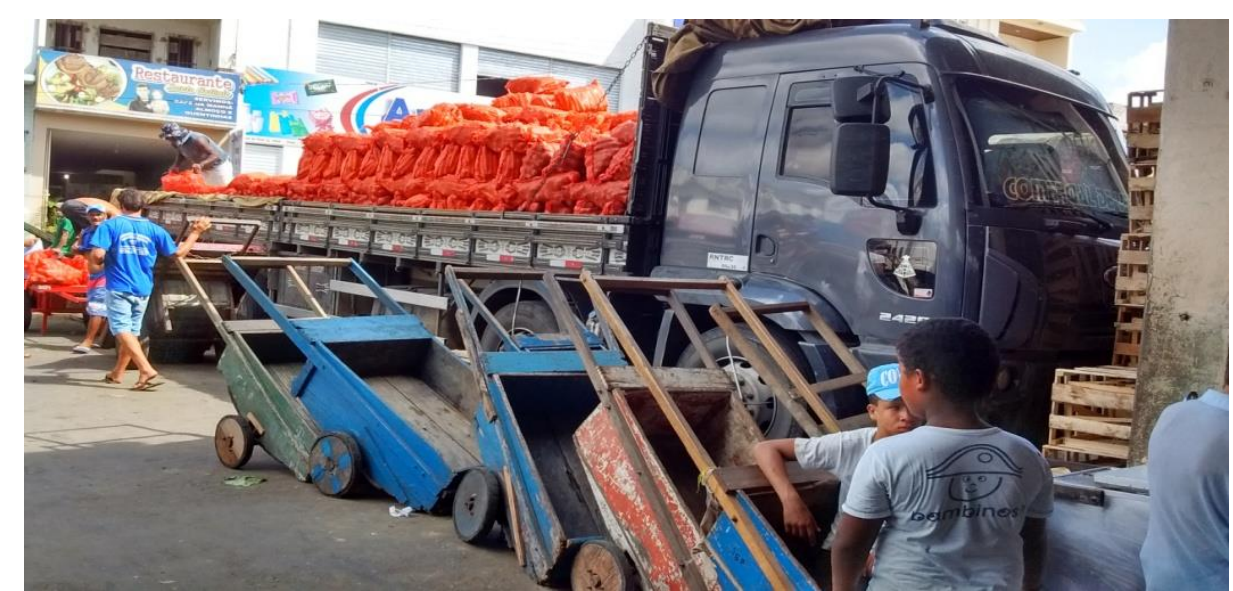

Figura 03: Descarga das mercadorias, Mercado municipal de Itabaiana.

Fonte: Trabalho de campo, abril 2016.

Com base nas entrevistas de campo realizadas na feira, evidenciou-se que a origem dos produtos se dá das mais diversas maneiras, ou seja, a partir do plantio e/ou venda de forma direta, essa sendo caracterizada pela proximidade entre a origem e o destino, já que em sua grande maioria, esses produtos comercializados de maneira direta, são colhidos dentro do estado de Sergipe. Os produtos comercializados por atravessadores, têm origem em várias partes do Brasil, como se pode observar na figura 02 a qual representa o momento da chegado de um carregamento de cebola oriundo da Bahia, além deste destacam-se os estados de Goiás, Alagoas, Pernambuco e Santa Catarina. Foi possível verificar que os principais produtos comercializados no mercado municipal de Itabaiana/SE, são batata doce, mandioca, tomate, banana, quiabo, feijão e o arroz, onde se observa a diversidade de produtos comercializados dentro do mercado, os quais são vendidos tanto na forma do atacado, quanto no varejo.

Verificando-se as informações contidas nas embalagens dos produtos comercializados no mercado municipal de Itabaiana/SE e que fazem parte da cesta básica de alimentação, foi possível observar que as origens desses produtos consumidos pelas famílias itabaianenses. Como principais produtos destaca-se o Açúcar oriundo de Laranjeiras/SE, o macarrão de Maceió/AL, o feijão preto de Feira de Santana-BA, o arroz de Ponte Alta-SC, e o extrato de tomate de Goiânia-GO. Por isso, a origem dos produtos comercializados dentro do mercado municipal de Itabaiana/SE pode ser dividida em escalas estadual e nacional. Na escala estadual (Sergipe) destacaram-se os produtos oriundos de Lagarto, Itabaiana, Itaporanga, Moita Bonita e São Domingos, na escala, nacional destacaram-se Bahia, Goiás, Alagoas, Pernambuco e Minas Gerais. Outra afirmação é possível fazer, no que se refere aos principais destinos das mercadorias, 
divididos com as mesmas escalas, ou seja, a nível estadual e nacional, a nível estadual destacou-se todos os municípios da microrregião do Agreste de Itabaiana, além de Carira e Aracaju. E a nível nacional destacaram-se, São Paulo, Goiás, Bahia, Alagoas e Pernambuco.

A partir dos questionários aplicados foi possível identificar que, a maioria dos produtos são comercializados no mercado municipal de Itabaiana são vendidos por atravessadores (cerca de $70 \%$ dos entrevistados) e que os comerciantes trabalham em média 14 horas por dia e cerca de 5 dias por semana e que não existe nenhum tipo de exigência para comercializar dentro da feira além do pagamento de uma taxa para que os caminhões possam ocupar os espaços em torno do mercado, por outro lado para que os produtos sejam aceitos pelo principal supermercado do município de Itabaiana/SE é exigido um selo fornecido pela prefeitura, no entanto a mesma não aplica nenhum tipo de fiscalização. Também observa-se que, os produtos que agregam valor, são oriundos de outros estados (extrato de tomate por exemplo), demonstrando assim como a maioria dos produtos oriundos da microrregião são comercializados no formato "bruto", revelando a dificuldade existente em agregar valor à produção, consequentemente, o atravessador compra a produção no "pé” e consegue transformar a matéria prima.

Foi constatado em diálogos com alguns agricultores, o fato de os mesmos terem tentado abandonar o trabalho com as atividades agrícolas, em virtude da exaustão do trabalho rural, e dessa maneira, buscaram trabalhar em áreas urbanas, mas devido ao baixo índice de escolaridade do agricultor, o emprego que era encontrado acabava sendo ainda mais cansativo e mal remunerado do que o encontrado na agricultura. Então, segundo um dos entrevistados "eu acabei voltando para a zona rural, devido ao custo de vida na cidade ser muito mais elevado, e ter apenas encontrado serviço como ajudante de pedreiro ou carroceiro" (A.J. S, Junho, 2015). Cabe destacar ainda que esses agricultores menos dinâmicos relatam que preferem adotar esse modo de vida pela aversão ao risco, além de em meio a conversas com os entrevistados, eles destacam que se houvesse orientação por parte do "governo" de como melhorar a lida no campo e mostrar os caminhos poderiam adotar um novo modo de vida, já que por não possuírem meios de incorporar novas técnicas, preferem continuar no modo de vida tradicional. A imagem a seguir destaca a diversificação das atividades no meio rural, as quais encontram se ligadas a pecuária, hortaliças e granjas, apontando para a presença da diversificação tanto das atividades, como dos ganhos dos agricultores analisados, dentro da unidade de produção familiar. 


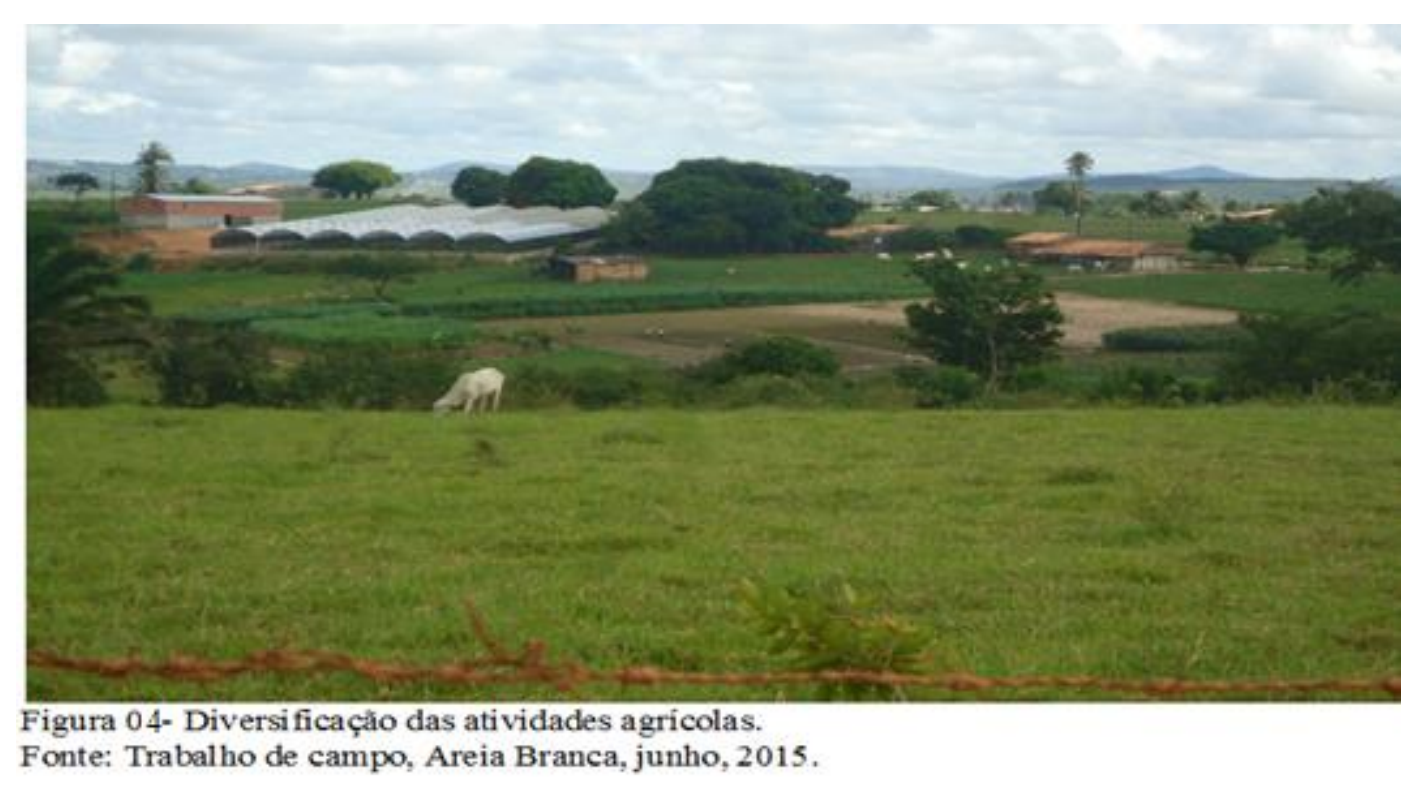

Os domicílios rurais visitados dedicam suas atividades agrícolas, principalmente, à produção de batata e mandioca, mas os agricultores relatam a grande dificuldade de lidar com esse tipo de produção. Os preços recebidos pelo que é produzido acabam sendo insuficiente, e de forma indireta é possível observar a presença marcante da figura do atravessador, o qual acaba estabelecendo um preço mínimo para o que é comercializado pelos agricultores, assim, encontram esses agricultores desorganizados no que se refere ao modo de inserirem sua produção nos mercados, os quais, em sua maioria, foram possíveis verificar que não fazem parte de nenhum tipo de associação ou cooperativa, facilitando assim a presença do atravessador, que acaba sufocando o agricultor com preços cada vez mais baixos pela mandioca ou pela batata.

Em um dos domicílios visitados no povoado Cova da Onça (Moita Bonita) o agricultor relata que chega a produzir 260 sacas por hectare, em uma propriedade de aproximadamente 5,5 ha, chegando a colher duas vezes ao ano e receber em média 20 reais por saca, envolvendo nessa produção oito irmãos que tem essa atividade como principal fonte de sobrevivência. No povoado Junco (Areia Branca), um determinado agricultor relata que em sua propriedade de aproximadamente 1 hectare consegue produzir aplicando mão de obra individual, cerca de 120 sacas anualmente, chegando a receber em média 80 reais por saca. Daí surge a dificuldade de calcular os reais ganhos dessas atividades para o agricultor, que na maioria das vezes, eles só conseguem citar o valor final recebido pela produção, com isso acabam agregando esses ganhos a outras rendas, como aposentadoria ou subsídio fornecido pelo governo federal, 
consequentemente, não sabendo o que foi gasto de fato para produzir determinada mercadoria e se ela gerou lucro ou de certa forma acabou gerando prejuízos.

Quadro 01- Valor anual médio arrecadado na produção de batata doce e mandioca em dois domicílios distintos do Agreste de Itabaiana/SE - 2015.

\begin{tabular}{|c|c|c|c|c|c|}
\hline \multicolumn{7}{|c|}{$\begin{array}{c}\text { Bacas por } \\
\text { hectare }\end{array}$} & $\begin{array}{c}\text { Tamanho da } \\
\text { propriedade }\end{array}$ & $\begin{array}{c}\text { Colheita } \\
\text { (anual) }\end{array}$ & $\begin{array}{c}\text { Preço por } \\
\text { saca }\end{array}$ & $\begin{array}{c}\text { Familiares } \\
\text { envolvidos }\end{array}$ & $\begin{array}{c}\text { Valor total } \\
\text { recebido } \\
\text { anualmente }\end{array}$ \\
\hline 260 & 5,5 ha & 2 vezes & 20 reais & 8 & 57200 reais \\
\hline \multicolumn{7}{|c|}{ Mandioca } \\
\hline $\begin{array}{c}\text { Sacas por } \\
\text { hectare }\end{array}$ & $\begin{array}{c}\text { Tamanho da } \\
\text { propriedade }\end{array}$ & $\begin{array}{c}\text { Colheita } \\
\text { (anual) }\end{array}$ & $\begin{array}{c}\text { Preço por } \\
\text { saca }\end{array}$ & $\begin{array}{c}\text { Familiares } \\
\text { envolvidos }\end{array}$ & $\begin{array}{c}\text { Valor total } \\
\text { recebido } \\
\text { anualmente }\end{array}$ \\
\hline 60 & 1 ha & $1 \mathrm{vez}$ & 70 reais & 1 & 8400 reais \\
\hline
\end{tabular}

Fonte: Trabalho de campo, elaborado por João Ernandes, Junho, 2015.

Com os dados colhidos a partir do trabalho de campo, é possível verificar que um agricultor envolvido no plantio da mandioca poderá arrecadar anualmente aproximadamente $\mathrm{R} \$ 7.150,00$, dessa forma, se não for levado em consideração o que esse agricultor tem de despesas durante o período entre o plantio e a colheita, ele chegará a uma arrecadação mensal inferior a $\mathrm{R} \$ 600,00$, com isso, o agricultor dedicado apenas ao plantio da batata doce, em que um período de um ano chega a arrecadar em média, $\mathrm{R} \$$ 8.400,00 reais, obtendo assim uma arrecadação média de $\mathrm{R} \$ 700,00$ mensais. Ressaltase que os cálculos são generalizados e refletem as informações coletadas a partir do trabalho de campo.

É possível destacar ainda a falta de capacidade ou recursos, para agregar valor ao que é produzido ou até mesmo utilizar o que é colhido como matéria-prima para a produção, de outras mercadorias, com isso, destaca-se a importância do Estado, que de forma mais ou menos indireta, acaba sendo citado pelos agricultores, uma vez que esse agente poderia atuar orientando esses agricultores de como utilizar o que é produzido, e até mesmo estruturando financeiramente esse grupo de agricultores. Mesmo assim, os agricultores familiares encontram-se parcialmente inseridos aos mercados, partindo do que é destacado em Abramovay (1990), que, esses agricultores passam por um processo de divisão social do trabalho dentro da unidade familiar, além de mesmo não apresentando racionalidade para gerir os ganhos, necessitam vender sua safra e comprar novos insumos para preparar-se para a nova safra. 


\section{Considerações finais}

Os dados e elementos apresentados nesse estudo servem para destacar alguns dos novos fatores presentes na agricultura contemporânea, além dos desafios da agricultura familiar do Agreste de Itabaiana. Sendo a feira e o mercado municipal de Itabaiana/SE, o local onde se tem a representação da relação rural/urbano, não apenas do município de Itabaiana/SE, mas também, do Agreste de Itabaiana/SE, tendo em vista que o município corresponde ao mais dinâmico e desempenha o papel de carro chefe dentro da microrregião analisada. Nesse sentido, destaca-se a relevância do agricultor ser dinâmico e empreendedor, frente às complexidades presentes no meio rural brasileiro contemporâneo, mas é preciso chamar a atenção para o ponto no qual não basta para o agricultor ser empreendedor se ele não estiver inserido em um contexto espacial que forneça - lhe elementos em que ele possa promover a auto sustentação do domicílio e ampliar os lucros, tendo em vista que, embora o meio rural do Agreste de Itabaiana, mesmo apresentando novas ruralidades, como áreas dedicadas aos turismo rural e casas de veraneio, também é marcado pela presença de famílias pobres e o envelhecimento da população.

Algumas questões podem ser consideradas como essenciais nas leituras e análises realizadas trabalho em questão, por exemplo: a possibilidade que se teve de conhecer e questionar de onde vem e o que é comercializado dentro do mercado de Itabaiana. Ao mesmo tempo, conseguiu-se verificar que nem tudo que é comercializado no mercado é oriundo do município de Itabaiana ou da Microrregião do Agreste de Itabaiana, assim como, observou-se qual o destino dos produtos comercializados dentro do mercado municipal, além de ser possível afirmar que nem sempre quem vende, é produtor, e que na maioria dos casos não existe nenhum tipo de fiscalização, referente à qualidade dos produtos.

Nesses termos, o meio rural da microrregião estudada não pode ser compreendido apenas como constituído por atividades agrícolas, em que se verifica a presença de novos empreendimentos e atividades, sejam eles ligados a atividades não agrícolas e/ou paraagrícola, sendo assim, surgem à necessidade de se discutir políticas públicas voltadas não apenas para os altos índices de pobreza presentes nesse meio, mas, também, atender à necessidade de inserção dos agricultores mais dinâmicos na competitividade e racionalidade econômica que é exigida nos dias atuais. Neste contexto, o referido estudo também busca fazer a relação que os novos empreendimentos agrícolas (antes presentes 
apenas nas áreas urbanas) tem na produção social do espaço, tendo em vista que a pobreza rural, ainda é um dos principais agravantes para o desenvolvimento rural, não apenas do Agreste de Itabaiana, mas também sergipano.

Consequentemente, a elaboração de políticas públicas, as quais consigam atender as demandas para os jovens agricultores, fazendo com que os mesmos, possam continuar residindo no meio rural, ou até mesmo, retornem trazendo novas experiências para a dinamização econômica da unidade familiar, como ocorre em outras regiões do país, sobretudo, na região Sul do Brasil, a qual destaca se pelo grau de modernização e especialização dos agricultores familiares, e, consequentemente, poderá ser adotada como referência pensando em longo prazo, desde que, sejam encontradas medidas para o fortalecimento da juventude rural nordestina.

Dessa maneira, a participação dos agricultores familiares, e principalmente da Juventude Rural, constitui-se como um dos elementos fundamentais para o direcionamento dos recursos destinados ao fortalecimento da agricultura familiar, em que, o meio rural do Agreste de Itabaiana/SE não pode ser caracterizado apenas como atrasado ou insustentável, pois foi possível observar grande diversidade na forma de se organizar dos agricultores familiares e a influência da urbanização nesse espaço geográfico. É por essa diversidade que se torna importantíssimo discutir de forma profissional e racional a aplicabilidade de investimentos para o meio rural e estratégias para assegurar as necessidades e os desejos dos jovens agricultores.

\section{Referências}

ABRAMOVAY, Ricardo. De camponeses a agricultores: os paradigmas do capitalismo agrário em questão. Campinas-SP: UNICAMP/IE (1990). (Tese de Doutorado).

ABRAMOVAY, Ricardo. Desenvolver os territórios fortalecendo o empreendedorismo de pequeno porte. $1^{\circ}$ Fórum Internacional território, Desenvolvimento Rural e Democracia. Relatório Final. Fortaleza, novembro 2003. 35 p.

CARDOSO, Jucyene das Graças. Agricultura familiar, pluriatividade e políticas públicas na região Nordeste e Sul do Brasil, nos anos 1990 e 2000: trajetórias de desafios. Uberlândia-MG: UFU/MG, 2013. (Tese de doutorado).

GRAZIANO DA SILVA, José, O novo rural brasileiro. Nova Economia, v. 7, n. 1. Belo Horizonte- MG, 1997. p. 43-81.

GRAZIANO DA SILVA, José. Os desafios das Agriculturas Brasileiras. In: A Agricultura Brasileira: desempenho, desafios e perspectivas / organizadores: José Garcia Gasques, José Eustáquio Ribeiro Vieira Filho, Zander Navarro. - Brasília: Ipea, 2010. p. 157-184. 
LEFÈBVRE, Henri. A cidade do capital. Rio de Janeiro: DP\&A, 2001.

LOPES, Eliano Sérgio A. A pluriatividade na agricultura familiar do Estado de Sergipe. In: Territórios Rurais e Agricultura Familiar no Nordeste. São Cristóvão: Editora UFS, 2009.

HARVEY, David. A produção capitalista do espaço. São Paulo: Annablume, 2005.

MENDES, Marcelo Alves. Agricultura familiar e novas ruralidades em questão: uma análise teórica. In: O fazer geográfico: teoria e prática. Organizadoras Márcia Eliane Silva Carvalho, Ana Rocha dos Santos. São Cristóvão: Editora UFS, 2013.

MENDES, Marcelo Alves. Os (des) caminhos geográficos e a pluriatividade na agricultura familiar: aspectos teóricos e cotidianidade da agricultura familiar no Nordeste. 1. ed. São Paulo: Novas Edições Acadêmicas, 2014. v. 200. 261p.

NASCIMENTO, Carlos A. do. Pluriatividade, pobreza rural e políticas públicas. Campinas-SP: UNICAMP/IE, 2005. (Tese de Doutorado).

NASCIMENTO, J. E. B; MENDES, Marcelo Alves. Dinâmica da agricultura familiar na Microrregião do Agreste de Itabaiana. Anais do VII Simpósio Internacional de Geografia Agrária. Goiânia-GO: Editora da UFG, 2015. v. Único. p. 579-592.

NASCIMENTO, J. E. B.; MENDES, M. A. A diversificação do trabalho como estratégia para o fortalecimento da agricultura familiar no Agreste de Itabaiana. In: Anais do 54 Congresso SOBER. Maceió: SOBER, 2016. v. 01. p. 1-20.

PIKETTY, Thomas. O capital no século XXI; Tradução Monica Baumgarten de Bolle. - I ed. Rio de Janeiro: Intrínseca, 2014.

ROCHA, Altemar Amaral; SANTOS, Geisa Alves dos. A dimensão do urbano e as relações de produção no povoado Santo Antônio - Barra do Choça/BA. In: Anais do XIV Simpósio Nacional de Geografia Urbana (SIMPURB). Fortaleza; 2015 p. 1-20.

SEN, Amartya. Desenvolvimento como liberdade. Tradução Laura Teixeira Motta - São Paulo: Companhia de letras, 2010. 461 p. $4^{\mathrm{a}}$ reimpressão.

SCHNEIDER, Sérgio. As atividades rurais não agrícolas e as transformações do espaço rural: perspectivas recentes. Publicado em Cuadernos de Desarrollo Rural. v. 1 n 44, Bogotá Colômbia, 2000, p. 11-40.

SCHNEIDER, Sérgio. Situando o desenvolvimento rural no Brasil: o contexto e as questões em debate. Revista de Economia Política, vol. 30, nº 3 (119), p. 511-531, julho-setembro/2010.

VEIGA, José Eli da. O Brasil rural precisa de uma estratégia de desenvolvimento. Brasília: Convênio FIPE - IICA (MDA/CNDRS/ NEAD) 2001.

\section{Dados coletados em:}

www.ibge.gov.com.br: Acessado em setembro de 2015;

http://www.brasil.gov.br/economia-e-emprego/2015/07/agricultura-familiar-produz-70-dosalimentos-consumidos-por-brasileiro: Acessado em setembro de 2015. 